\title{
Balance lost: what sustainability?
}

\author{
M. Soygenis ${ }^{1} \&$ S. Soygenis ${ }^{2}$ \\ ${ }^{1}$ Yildiz Technical University, Turkey \\ ${ }^{2}$ Bahcesehir University, Turkey
}

\begin{abstract}
Turkish cities, architecture and lifestyle were all ecology-friendly until the breaking point of transformation of cultural issues, living habits and physical environment. Traditional large families lived in one or two story houses with courtyards where the design of houses and the neighborhoods were utilizing basic design approaches such as proper siting and orientation of buildings, interior and exterior spaces, friendly living with nature taking benefit of the sun, topography and vegetation. After the 1950 s, rapid population increase in modern Turkey brought with it problems such as re-structuring of existing traditional environments due to the increasing urban population as a result of migration and urban sprawl. Uncontrolled urban sprawl meant unplanned re-structuring and socalled 'development' of existing urban environments. Unfortunately the natural balance of urban and architectural environments were lost during the false urbanization process and authorities including governments, NGO's and universities in Turkey are now trying to restore the situation with a hope of bringing it back to humane conditions under the name of 'sustainability'. Considering sustainability is the process of maintaining ecological systems at a certain level indefinitely, in the Turkish case, success is a utopia; or the question is at which level should the environment be maintained? At the level before the 1950s?
\end{abstract}

Keywords: traditional housing, sustainability in Turkish cities, urban fabric, climate responsive architecture.

\section{Introduction}

Monuments, housing and urban spaces in between, together with the natural environment coexisted and formed the grand panorama of cities. While there may be variations, cities are shaped according to these elements. Human beings 
with various lifestyles and cultures influenced the formation of different settlements i.e. cities. Culture and lifestyles together with changes in production systems, new inventions, construction techniques and technological developments provided vital thresholds for the transformation of the built environment. Life in caves, agriculture and stockbreeding as means of production explain the formation of physical conditions of the environment. Consequently the environment of the tribes and settlers varies depending on their lifestyles.

The relationship between the lifestyle and the built environment also exists between the built environment and the natural environment. The comfort and well being of people depend on the balanced relationship between the two. People, especially in the West, used technology and its developments as a means of controlling nature and its forces. What was vital in this relationship was to remember that controlling nature did not involve defeating nature. Unfortunately people were not successful in maintaining this equilibrium, which resulted in the loss of balance in the natural environment due to the developments of the built environment. Pollution in the natural environment and cities became an agenda in many geographies, sustainability and ecological balance became one of the leading issues of many disciplines in this decade.

\section{Sustainability}

There is consensus among researchers, designers, even politicians on the concern for the natural and built environment. People began to realize that they had not been very friendly towards the environment and as it stands, the next generation is at risk in terms of what has happened to the environment. The pollution of air, sea and land are threatening the natural life. Cities that were once the symbol of civilization became overcrowded, polluted and over built without concern for the need for the green. These developments opened the way for questioning the relationship between nature and the built environment. Those that were concerned with the natural environment started this discussion on 'saving the World'. The original term 'green' used by the designers changed into 'eco' then to 'sustainable' reflecting the broadening of the subject in theory and practice (Madge [1]). While some sources mentioned the term's usage dating to the 1970 's, the first use of the word sustainability according to Steele goes back to 1980 in a publication titled the 'World Conservation Strategy' and it was related to development (Steele [2]). Sustainability is an ecological term. It can be defined as 'the capacity of a system to maintain a continuous flow of whatever each part of that system needs a healthy existence' (Madge [1]). The publication produced by the 1992 Rio Summit provided a comprehensive outline of sustainable development. This document summarized this complex problem into six subject areas, such as; the quality of life on earth, the efficient use of earth's materials, the protection of our global commons, the management of human settlements, chemicals and the management of waste and sustainable economic growth (Steele [2]). Among this very complex and wide topic, our concern in 
this paper is limited to the discussion of the management of human settlements, specifically the traditional housing settlements in Turkey.

\section{Aim}

The aim of this paper is to discuss the traditional residential architecture of Turkey in relation to sustainability and pinpoint the loss of eco-concepts that are inherent in traditional architecture through a review of urban scenes from various regions in Anatolia.

\section{Turkish case}

The development of residential architecture in Turkey and consequently the traditional Turkish city reflect the lifestyles of its inhabitants, at the same time providing a physical environment that cares for climatic requirements, i.e. usage of passive systems in terms of urban fabric and building materials. In the golden ages of the Ottoman Empire, families were large. Cities were formed by the social units called the 'mahalle'. In this context, the house was the private unit, the atrium, the semi-private and the street, the public. The built environment in cities comprised of relatively permanent monuments and relatively temporary and variable elements, namely housing. Buildings that were open to the public were constructed with relatively permanent building materials such as stone and brick. Although it differs from region to region, wood was used in the construction of houses and palaces, paralleling the belief of life being temporary. The architecture of housing in Anatolia reflected the character of each region according to the climate and availability of materials, as well as the lifestyle of its inhabitants.

The hierarchical relationship between the individual, family and society, the family being the smallest unit of the society, and differentiation between public and private, are reflected in the introvert type courtyard housing and the public area comprising a mosque, market place, coffee house and Turkish bath (Hourani [3]). In other words public, semi-private and private areas form the hierarchical subdivisions in the urban areas (Petherbridge [4]). This hierarchical and closed system is a tool for pedestrian oriented planning which provides limited vistas and walking distances in contrary to the gridal plans (Fathy [5]). In Mediterranean cultures as in the case of Turkish city, streets are designed for pedestrian movement and there is a hierarchical flow from the house to the courtyard, to the street and public areas (Rudofsky [6]).

According to some researchers, the traditional Turkish house, which is the smallest unit in the morphology of the Ottoman city, originated from Anatolia and spread into Europe parallel with the sprawl of the Ottoman Empire (Eldem [7]). The Anatolian house when transferred to Balkans and named the Balkan House in that geography kept its original characteristics with some local cultural variations.

Some authors based the morphology of the Anatolian house on the traditions of Asian nomadic life, which is cultivated on the nomadic culture and its strong 
relationship with the land. These traditions reflected on the built form as formation of central space, an introvert, elevated living flat with a wooden floor and ceiling slabs that were similar to those of the nomadic tents (Aksoy [8]). In parallel with the sprawl of the Ottoman Empire, the Turkish house tradition was carried to some African countries such as Egypt and Sudan.

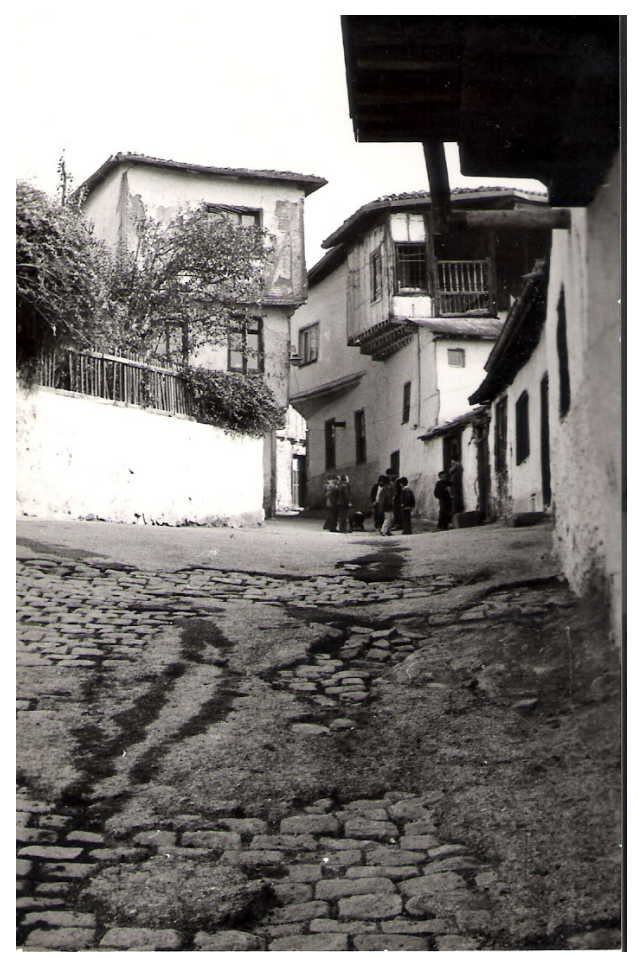

Figure 1: $\quad$ Street and courtyards provide comfortable microclimate zones in the central Anatolian town, Ankara.

The basic formation of the Turkish house, which is influenced by various cultural, climatic and topographic conditions, stems from the Turkish civilization, life and house culture (Eldem [9]). Analysis of the traditional Turkish urban fabric through the social structure and lifestyles of the neighborhoods 'mahalle' reveal variations according to the climatic conditions. Climatic conditions are milder in coastal areas and become harsh as one gets inland. The morphology of the organic fabric of the Turkish city depends on the climate. In hot and dry climates the house patterns are introvert. The streets are narrow and shady. In cold climates similarly introvert and dense fabric is present. In milder climates, the house opens to the sun but closes to rain and cold. The houses are scattered and the urban fabric is less dense (Aru [10]). In the traditional Turkish city, the topographic structure plays a decisive role along with the climatic conditions. In cities that are located on plains, the urban fabric 
is less dense and organic. In valleys, due to the insufficient flat terrain, the development is linear and it is parallel to the shoreline. On hillsides and sloping areas, a dense urban fabric with narrow lots is formed where houses sit on the slopes. As it gets to the top of the hill, streets surround the city as curvilinear paths parallel to the topography.

The formation of the Turkish city depends on, and is in harmony with, the climate, topography and social structure. An urban order, responsive to climate and topography could easily be adapted to the variations in nature, providing cool breezes to penetrate deep into the streets. Courtyard and house layouts, protected by the sun through narrow streets in summer time, made it possible to have climatic comfort in each sub element in the hierarchy of the urban fabric.

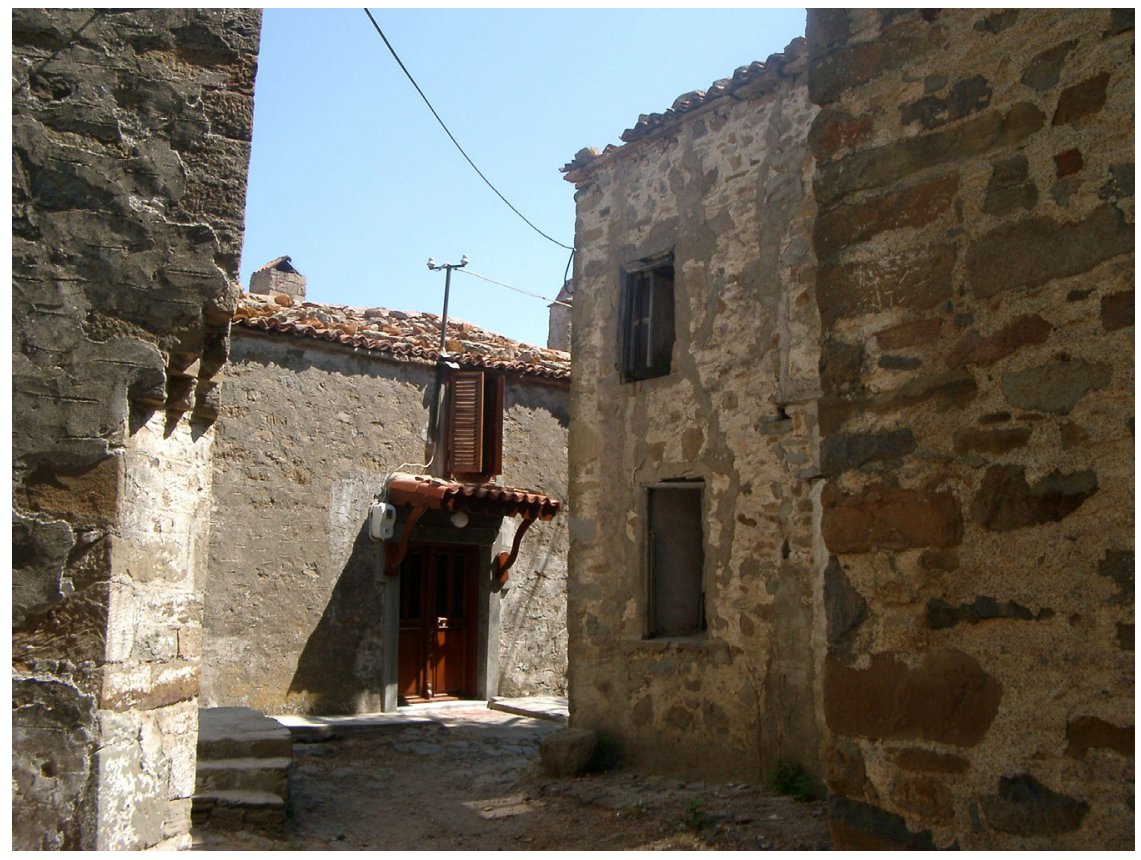

Figure 2: $\quad$ Narrow streets provide shady pedestrian routes in the northwestern island of Gokceada.

The typical Turkish house plan is made of rooms, with a sofa and courtyard in between rooms. This morphological hierarchy responds to the family lifestyle, creates a hierarchy of private and semi-private spaces in the house and at the same time provides a climatic response in plan layout. Materials such as wood, stone and mud are used according to the climatic characteristics of each geographic region and various wall sections are designed to resist various climatic conditions. Being the sub element of each plan typology, the courtyard and sofa vary with the climate providing plan types that have open or closed sofas. Openings to the courtyard and street are designed in harmony with nature, varying with topographic and climatic conditions (Alsac [11]). The existence of 
summer and winter rooms in the house provide settings that have appropriate micro climatic comfort. Summer rooms being larger and higher are located looking towards the exterior while winter rooms are located in the mid portions of the house where protection from the outside is easily provided. The openings in the summer rooms are kept larger while in winter rooms there are a few small openings. Winter rooms also include a stove for heating. The summer room, opening to the mild breeze, is placed on a corner location in the upper level. Wide windows make it possible for the breeze to penetrate into the interiors. Since summer rooms are used for long periods of time, these spaces are planned accordingly. In these rooms, floors, ceilings and walls are constructed with materials that provide air penetration. The winter rooms are located on the mezzanine level, closed to the winds with small openings, thick and insulated walls (Eldem [12]).

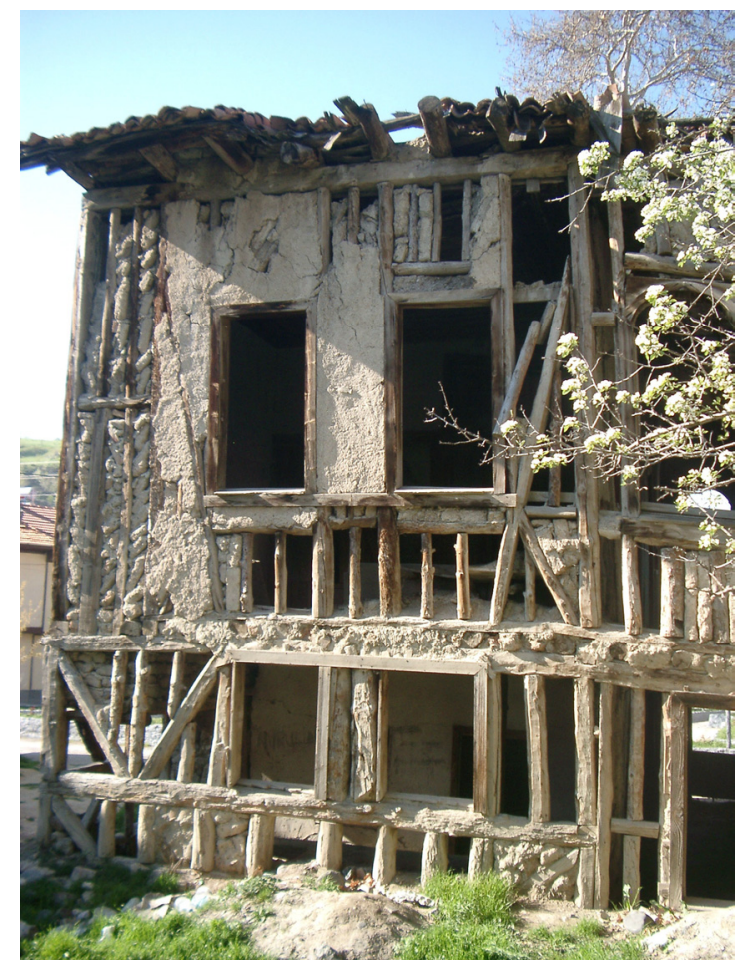

Figure 3: Timber structure and mud infill provide a climate sensitive skin as well seismic resistance for this abandoned house in the western Anatolian town of Eski Gediz.

Traditional houses that are located in the various climatic regions of Turkey are built according to the climatic conditions and available materials specific to that region. Cities in the eastern and southeastern regions are of introvert type while in the western and southern regions they are extravert. In the Marmara 
region where a moderate climate is present, houses are two or three storys high and constructed from wood. In the Karadeniz region where the climate is mild with rain, the construction material is basically wooden. In the Akdeniz region, depending both on the climate and topographic characteristics, the urban morphology lets sea breezes deep into city, even into the atriums of houses. Streets in this region are kept narrow as to provide shade in the summers where the sun's rays hit the earth almost at right angles. Walls are white washed to reflect the sun. In the mid Anatolian regions, in response to fluctuating summer and winter temperatures, ground levels are constructed with thick walls and are for winter use, while in the upper floors the walls are thinner to let infiltration in and are for summer use. Wide eaves are provided for sun and rain protection. In southeastern Anatolia, streets are narrow and shady for sun protection, the buildings open to the exterior with limited openings, and buildings are connected to each other through bridges that provide shade to the streets. Due to the dry climatic characteristics, the buildings have a flat roof and stone is used as a building material, due to its availability (Aru [10]).

As the influences of westernization, and changes in the social, economic and administrative structure of cities reflected on the family structure, the family as a unit became smaller, similarly the housing that they dwelled in became smaller. An increase in urban population and density and frequent fires in the city changed the urban fabric, the renewed roads and parcels created a new urban fabric. The spatial hierarchy of the house began to change with the urban life in the neighborhoods due to new administrative and social structure. The spatial order of street, atrium, sofa and room diminished and changed into a direct access to the house from the street. After the mid nineteenth century, row houses and multi unit apartments as new apartment types started to appear in the urban morphology. Segregation due to social class that was not apparent before started to appear in the urban fabric, some neighborhoods developed into multi-unit apartment neighborhoods that were favored by the well to do (Duben [13]).

During the period starting from the Republic until the 1950s, westernization had been taken too seriously by the administration and interpreted as resembling the Western lifestyle by all means and costs (Kongar [14]), which resulted in overcrowded cities and eradication of the traditional Turkish city whose typical characteristic is being in harmony with the climate, topography and lifestyle.

\section{Urban sprawl in the 1950s}

With the Republican period, house plan layout and construction materials for houses changed parallel with the transformations in social, economic and ideological structure. Transformations that were apparent in the houses of the well to do later spread to the houses of middle income people. The typical plan type comprising of multi-purpose rooms with sofa transferred to a house type where each room housed a different function.

Starting from 1950s, the population rise in large cities accelerated with migration from rural areas. Istanbul, Ankara and Izmir, the three largest cities of Turkey housed $30 \%$ of the whole population. Due to this population increase, the 
existing housing stock and the new production became insufficient, which resulted in the development of squatter settlements without any infrastructure, surrounding the cities.

Eco-conscious traditional 'mahalle' fabric is replaced by the apartment buildings that were multi-story or tower blocks comprising of one or multi-units on the same level. This new house type is generally designed with no concern for climatic, topographic factors or lifestyles of its inhabitants resulting in an

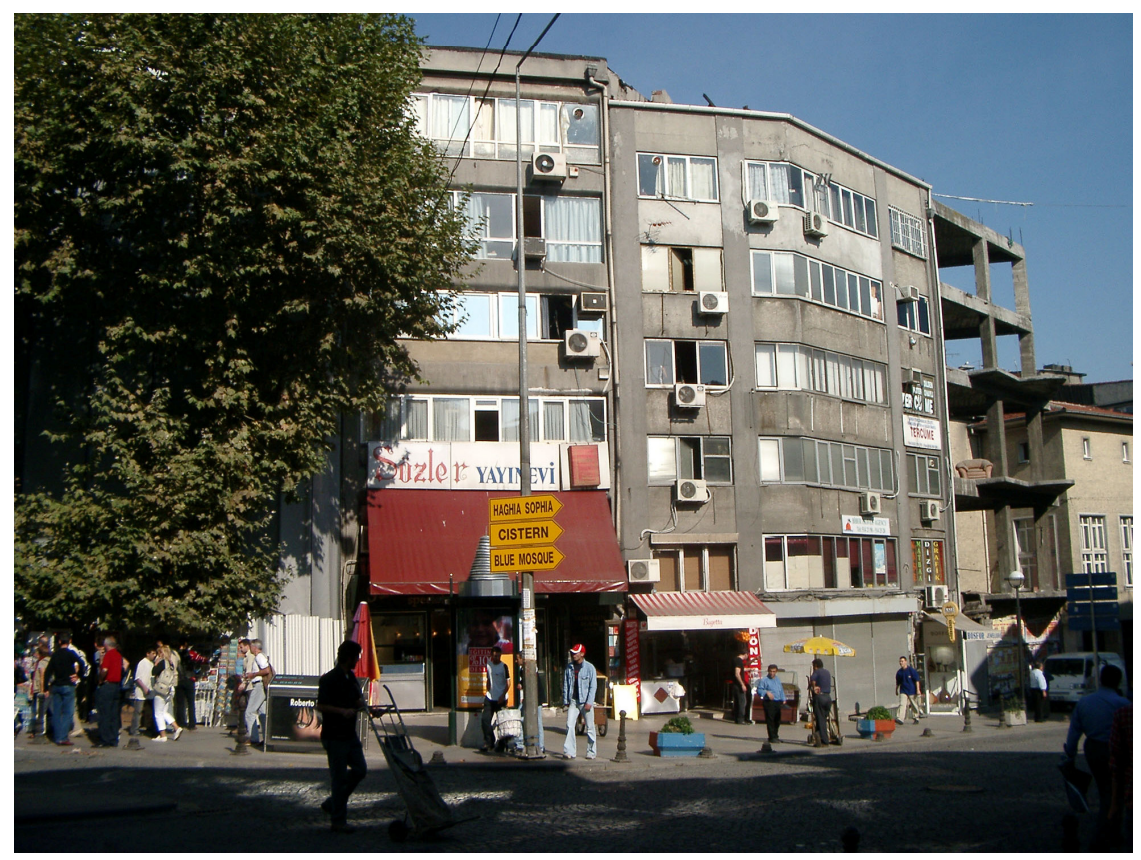

Figure 4: Multi-story apartment buildings in Istanbul with no concern for climatic factors.

increase of the urban density, insufficient green areas, creating overloaded urban infrastructure and an environment where climatic concerns were either insufficient or completely dismissed. In the plan layout the winter and summer rooms were displaced by randomly dispersed rooms. The urban fabric that has been formed depending on the climatic zones was replaced with one housing type that fits all climates. Wall sections specific to each climate zone were replaced with a single type, a brick wall with both sides plastered, for all regions. Instead of the well ventilated rooms, natural ventilation was not a concern any more. Those people that were accustomed to living both in the room with an adjoining sofa and garden were confined to a lifestyle in the multi-story units where there was no direct relation between the interior and the garden. The urban fabric that was responsive to climatic conditions, light and shade balance, 
changed into a fabric where it is not possible to get light and fresh air into the interiors of buildings.

\section{What can be done?}

The ecological balance of Turkish cities has been in an accelerated degeneration since 1950. The balance between the built and natural environment that was present in the typical Turkish city has diminished. Environmental pollution - air and noise - has reached a life threatening level. The so-called urbanization process in Turkey motivated by the regulations imposed by the administrations, ended up with the loss of traditional urban fabric instead of replacing the old with better settlement solutions. Currently the urban environments that are subject to sustainability in Turkish cities are very scarce. Yet public institutions and universities are providing the society with ideas and information on how to upgrade the environment and make it livable. This is contradictory with respect to sustainability because there seems to be very limited noteworthy environment to be saved. In that respect, the sustainable development of the existing cities is a utopia since the unplanned growth after the 1950s caused the loss of built and natural balance. It is almost like revitalizing something that is not present. The aim is not to develop tactics for sustainability of the traditional environment, it is to stop or stabilize the plunder. It is too late to sustain the 'sustainable' traditional architecture in Turkey, yet it is time to look at the traditional architecture in terms of hidden eco strategies and apply them as key design criteria for future developments.

\section{References}

[1] Madge, P., Ecological Design: A New Critique, Design Issues, 13(2), pp. 44-54, 1997.

[2] Steele, J., Sustainable Architecture: Principles, Paradigms and Case Studies, McGraw-Hill: New York, 1997.

[3] Hourani, A.H., The Islamic City in the Light of Recent Research, The Islamic City / A Colloquium, ed. A.H. Hourani, S.M. Stern, Bruno Cassirer Oxford and University of Pennsylvania Press: Oxford, pp. 9-24, 1970.

[4] Petherbridge, G.T., Vernacular Architecture: The House and Society, Architecture of the Islamic World, ed. G. Mitchell, Thames and Hudson: New York, pp. 176-208, 1987.

[5] Fathy, H., Constancy, Transposition and Change in the Arab City, From Madina to Metropolis: Heritage and Change in the Near Eastern City, ed. L.C. Brown, The Darwin Press: Princeton, pp. 319-334, 1973.

[6] Rudofsky, B., Streets for People / A Primer for Americans, Doubleday and Company Inc.: Garden City, 1969.

[7] Eldem, S.H., Turk Evi Plan Tipleri (Turkish House Plan Types), ITU Mimarlik Fakultesi: Istanbul, 1954. 
[8] Aksoy, E., Ortamekan: Turk Sivil Mimarisinde Temel Kurulus Prensibi (Central space: Basic Structural Principle in Turkish Civil Architecture), Mimarlik ve Sanat, 7-8, Istanbul, 1963.

[9] Eldem, S.H., Turk Evi - Osmanli Donemi (Turkish House - Otoman Period), 1, TAC Vakfi: Istanbul, 1984.

[10] Aru, K.A., Turk Kenti (Turkish City), YEM Yayin: Istanbul, 1998.

[11] Alsac, U., Turk Mimarligi (Turkish Architecture), Iletisim Yayinlari - Cep Universitesi: Istanbul, 1992.

[12] Eldem, S.H., 17 nci ve 18 inci Asirda Turk Odasi (Turkish Room in 17th and 18th Centuries, Guzel Sanatlar Dergisi, 5, Maarif Vekilligi Yayini: Istanbul, pp. 1-28, 1944.

[13] Duben, A., Behar, C., Istanbul Households / Marriage, family and fertility 1880-1940, Cambridge University Press: Cambridge, 1991.

[14] Kongar, E., Imparatorluktan Gunumuze Turkiye’nin Toplumsal Yapisi (Societal Structure of Turkey from Imperial Times to Today), Cem Yayinevi: Istanbul, 1978. 